\title{
Distrofia miotônica tipo 1 em pacientes com catarata: diaǵnóstico molecular para triagem e aconselhamento genético
}

\author{
Myotonic dystrophy type 1 in cataract patients: Molecular diagnosis for screening and \\ genetic counseling
}

\author{
María Verónica Muñoz Rojas ${ }^{1}$ \\ Leila Maria Cardão Chimelli² \\ Aguinaldo Luiz Simões ${ }^{3}$
}

Trabalho realizado nos Departamentos de Patologia e de Genética e Matemática aplicada à Biologia da Faculdade de Medicina de Ribeirão Preto da Universidade de São Paulo.

${ }^{1}$ Médica Geneticista da Clínica Materno-Fetal, Florianópolis. Mestre em Medicina - Patologia Experimental pela Faculdade de Medicina de Ribeirão Preto da Universidade de São Paulo - USP

${ }^{2}$ Professora Titular do Departamento de Patologia da Faculdade Medicina da Universidade Federal do Rio de Janeiro. Livre Docente em Patologia pela Faculdade de Medicina de Ribeirão Preto da Universidade de São Paulo - USP.

${ }^{3}$ Professor Livre-Docente e Doutor pelo Departamento de Genética e Matemática Aplicada à Biologia da Faculdade de Medicina de Ribeirão Preto da Universidade de São Paulo - USP.

Endereçopara correspondência: María Verónica Muñoz Rojas - Av. Rio Branco, 380/1103 - Florianópolis (SC) CEP 88015-201

E-mail: veronicamunoz@terra.com.br

Fontes de auxílio à pesquisa: Fundação de Amparo à Pesquisa do Estado de São Paulo - FAPESP.

Recebido para publicação em 02.03.2004

Versão revisada recebida em 10.11.2004 Aprovação em 11.11.2004

Nota Editorial: Pela análise deste trabalho e por sua anuência na divulgação desta nota, agradecemos à Dra. Juliana Maria Ferraz Sallum.

\begin{tabular}{l} 
RESUMO \\
\hline Objetivos: Detectar novos pacientes portadores da mutação e pré-mutação \\
da DM1, entre pacientes com catarata e realizar aconselhamento genético. \\
Métodos: Foi estudado o DNA de 60 pacientes, por meio da análise por \\
reação em cadeia de polimerase. Este estudo foi realizado no Hospital das \\
Clínicas da Faculdade de Medicina de Ribeirão Preto e os pacientes foram \\
selecionados a partir dos atendimentos realizados no Ambulatório de \\
Catarata do Departamento de Oftalmologia, entre 01/01/1982 a 30/06/1995. \\
Os critérios de seleção foram pacientes com menos de 55 anos, com catarata \\
bilateral, sem fator causal que justificasse a lesão, exceto por diabete melito \\
tipo 2 com ou sem sinais neuromusculares sugestivos de distrofia mio- \\
tônica. Resultados: Foram encontrados 3 pacientes com a mutação com- \\
pleta, correspondendo a 5\% da amostra. Nenhum portador da pré-mutação \\
foi encontrado. A partir dos pacientes diagnosticados, outros familiares \\
afetados foram detectados. Conclusões: Este estudo enfatiza a importân- \\
cia da triagem de distrofia miotônica tipo 1 (DM1) entre pacientes com \\
catarata, e mostra, também, a importância do aconselhamento genético \\
destes pacientes.
\end{tabular}

Descritores: Catarata; Diagnósticos diferenciais em catarata; Genética molecular; Distrofia miotônica

\section{INTRODUÇÃ̃O}

A catarata pode ser atribuída a um fator genético. Freqüentemente, quando isto ocorre, a causa subjacente é uma desordem metabólica, como no diabetes, na doença de Fabry, na galactosemia, em alguns tipos de mucopolissacaridose, na deficiência de G6PD, no pseudo-hipo-paratireodismo, entre outros. Algumas alterações cromossômicas também costumam apresentar catarata em sua constelação de sinais e sintomas, como na síndrome de Down, na síndrome de Patau e na síndrome de Edwards. Alterações dermatológicas também podem cursar com catarata, como nas ictioses e nas displasias ectodérmicas. Entre as desordens neuromusculares, a catarata é um achado importante na Distrofia Miotônica tipo 1 (DM1), Distrofia Miotônica tipo 2 (DM2) e na miotonia associada a miopatia miotubular ${ }^{(1-2)}$.

A DM1, ou distrofia miotônica de Steinert, é uma doença autossômica dominante que pertence ao grupo das doenças causadas por mutações dinâmicas $^{(3-5)}$. As mutações são chamadas dinâmicas porque existe uma seqüência de nucleotídeos que se repete sucessivamente, de tal forma que os 
alelos normais podem ter tamanhos variáveis dependendo do número de repetições que apresentam. Quando o número de repetições se torna muito extenso, o alelo perde a estabilidade e ocorre um erro na leitura do número de repetições. Isto faz com que algumas cópias sejam replicadas mais de uma vez. Como conseqüência são formados alelos com número de repetições maior do que o original, e por isso as mutações aumentam de uma geração à outra, muitas vezes de forma significativa, causando a alteração estrutural e/ou funcional de determinadas proteínas, que se traduz por mecanismos patogênicos.

A DM1 é caracterizada por miotonia, distrofia muscular, catarata, hipogonadismo, calvície frontal e alterações eletrocardiográficas, e foi delineada como uma entidade clínica distinta em 1909 por Steinert ${ }^{(6)}$. A DM1 é a forma de distrofia muscular mais comum do adulto. Sua incidência no Brasil ainda não foi determinada e de forma geral varia entre 1:70008500 nascimentos $^{(7)}$. Ela não é apenas a desordem miotônica mais comum, mas também a mais variável e, em muitos casos, a mais grave. É a única doença miotônica onde ocorrem alterações musculares distróficas progressivas significativas e que, apresenta envolvimento sério de outros sistemas, além do músculo-esquelético ${ }^{(8)}$. As características clínicas são muito variáveis e a doença pode se apresentar desde a forma assintomática até a forma congênita grave. Os pacientes afetados têm risco aumentado para arritmias cardíacas e complicações anestésicas de forma geral. A DM apresenta o fenômeno da antecipação, ou seja, nas gerações sucessivas a doença, em geral, apresenta seus sintomas mais precocemente e se torna progressivamente mais grave ${ }^{(9)}$.

Desde 1918, observou-se que diversos grupos familiares com doença de Steinert eram freqüentemente reconhecidos através de catarata, mas sem sinais musculares óbvios ${ }^{(10)}$.

O conhecimento da base molecular por trás da DM1 vem avançando com a elucidação, em 1992, da localização do gene da miotonina proteína quinase (MT-PK) em 19q 13.3, o qual contém uma repetição instável do trinucleotídeo citosinatimina-guanina $(\mathrm{CTG})^{(11)}$. A mutação que causa a doença é a expansão de uma repetição do trinucleotídeo CTG na região 3 não traduzida do gene da MT-PK O tamanho da repetição CTG encontrada na população normal é variável, apresentando entre 5 e 37 cópias $^{(3-5)}$, enquanto os afetados apresentam entre 50 a mais de 2.000 cópias. Quando um alelo tem entre 38 e 100 cópias, é chamado de pré-mutação ${ }^{(11-12)}$. Os alelos podem ser analisados utilizando amplificação de DNA através de PCR (reação em cadeia de polimerase) e posterior análise quando os fragmentos são menores e correspondem a alelos normais, com a pré-mutação ou alelos expandidos mas com número menor de repetições, ou utilizando análise através de Southern blot, para fragmentos maiores, com grande número de repetições presentes nos indivíduos afetados ${ }^{(13-14)}$. Em geral, quanto mais acentuado for o fenótipo, maior será o alelo expandido. Assim, espera-se que os pacientes com a forma mínima da doença, alguns dos quais podem ter apenas catarata como único sintoma, apresentem os menores alelos expan- didos, enquanto aqueles com a forma congênita apresentem as maiores expansões. Apesar da existência da correlação entre a apresentação clínica e o tamanho da expansão, esta correlação não é exata, e o número de repetições CTG não pode ser utilizado para prever precisamente a forma clínica de um paciente.

Em 1998, foi mapeado e descrito um segundo lócus para distrofia miotônica (DM), no cromossomo $3 \mathrm{q} 21^{(15)}$. A partir deste momento ficou definido como DM1 (OMIM 160900)(16) aquela causada pela expansão CTG no cromossomo 19 e DM2 (OMIM 602668) $^{(16)}$ aquela causada por uma mutação no cromossomo 3. A DM2 é causada por uma mutação dinâmica através da expansão de uma seqüência repetitiva de 4 nucleotídeos repetitivos CCTG localizada no íntron 1 do gene da proteína zinc finger 9 (ZNF9). Apesar do fenótipo da DM1 e DM2 serem muito semelhantes, eles não são idênticos, uma vez que a DM2 não apresenta a forma congênita de DM. Assim como na DM1, a expansão CCTG da DM2 é localizada numa região transcrita mas não traduzida do gene ${ }^{(3)}$. Acreditase que a explicação para o fenótipo da DM1 e da DM2, seja um ganho de função no nível de RNA, ou seja, as expansões CTG e CCTG resultariam na produção de um transcrito de RNA prémensageiro anormal, o qual não sofreria o processamento $\mathrm{e}$ recomposição do RNA (splicing) ficando retido dentro do núcleo celular. Neste caso, os sintomas da DM1 e DM2 seriam decorrentes de níveis muito baixos da proteína normal, e/ou da toxicidade nuclear causada pelo acúmulo de transcritos de RNA mensageiro ${ }^{(5,16-17)}$.

Em 1995 um grupo de pesquisadores propuseram a triagem de DM1 em pacientes portadores de catarata bilateral antes dos 55 anos de idade e sem fator causal aparente ${ }^{(10)}$.

Este trabalho tem como objetivos (1) avaliar a aplicabilidade do método proposto para triagem de catarata ${ }^{(10)} \mathrm{em}$ nosso meio direcionando a triagem para DM1; (2) verificar a existência de novas famílias portadoras de DM1; (3) oferecer aconselhamento genético familiar em relação à DM1, nos pacientes afetados.

\section{MÉTODOS}

Foi realizado um levantamento dos pacientes que haviam sido atendidos por apresentarem catarata em ambos os olhos e que tivessem menos de 55 anos de idade. Este levantamento foi realizado através dos Serviços de Arquivos Médicos do Hospital de Clínicas da Faculdade de Medicina de Ribeirão Preto (HCFMRP). Foi feita a revisão de cada prontuário, procurando o fator causal da catarata. Foram excluídos os pacientes com história de trauma ocular, com doenças sistêmicas e em uso de medicamentos variados e, pacientes com cromossomopatias ou outras síndromes genéticas ou com catarata congênita. Não foram excluídos os pacientes com diabete melito tipo 2. 
Inicialmente, a seleção dos pacientes seguiria os seguintes critérios: (1) pacientes com menos de 55 anos de idade, com catarata bilateral e sem fator precipitante demonstrável, exceto diabete melito tipo 2; (2) pacientes de qualquer idade com cristais policromáticos ${ }^{(10)}$. No entanto, não foi possível incluir o segundo critério devido a limitações de descrição da alteração do cristalino no prontuário médico, visto que se tratou de uma seleção retrospectiva.

Todos os pacientes selecionados haviam sido atendidos no Ambulatório de Catarata do Departamento de Oftalmologia do HCFMRP, no período de 01/01/1982 a 30/06/1995. Este estudo foi previamente aprovado pela Comissão de Ética do HCFMRP.

Sessenta pacientes compareceram e concordaram em participar do estudo. Aqueles com resultados negativos para DM1 foram informados através de correspondência e aqueles com resultados positivos ou inconclusivos foram convidados a comparecer novamente para continuar a investigação e o aconselhamento genético. Aconselhamento genético e investigação dirigida para DM1 foram oferecidos para outros membros da família através do propósito de cada heredograma.

Foi extraído DNA de sangue periférico através de métodos convencionais. A padronização da PCR para amplificação do DNA e posterior análise da quantidade de repetições de trinucleotídeos CTG, no gene da DM1, através da verificação do tamanho dos fragmentos amplificados pela PCR nos dois alelos dos indivíduos estudados, foi inicialmente tentada utilizando os primers 101 e $102^{(11)}$ sem obtenção de resultados. A PCR foi padronizada, então, segundo outro protocolo ${ }^{(18)}$. As amostras foram aplicadas juntamente com um "ladder" (marcador de tamanho escalonado) de 50 pares de base ou com marcadores de peso conhecido em um gel de poliacrilamida a $12 \%$, a $300 \mathrm{~mA}$. Após a eletroforese, as bandas foram identificadas através da coloração pela prata. Este protocolo permite a detecção de alelos contendo de 5 (77 pb) até 140-150 (>500 pb) repetições CTG, mas amplificações com mais de 100 repetições CTG não são fidedignas e não foram consideradas.

Os pacientes com resultados inconclusivos, pela análise dos fragmentos amplificados pela PCR, foram convidados a realizar estudo eletroneuromiográfico como exame de investigação complementar. A presença de descargas miotônicas foi pesquisada no repouso, após a movimentação da agulha e após a percussão muscular.

Os pacientes afetados foram convidados a realizar biópsia de músculo. Foi retirado um fragmento de músculo do bíceps direito, sob anestesia local. Uma parte desse fragmento foi fixado em formol a 10\% e processada para inclusão em parafina. Estes cortes foram corados pela hematoxilina e eosina e pelo tricrômico de Gomori. Outra parte foi congelada em nitrogênio líquido para as reações histoenzimológicas e, posteriormente, cortes foram preparados e incubado em meios apropriados para demonstrar as atividades das enzimas adenosina-trisfosfatase a pH 9,4 (ATP-A 9,4), sem pré-incubação e com pré-incubações a pH 4,6 e pH 4,3; nicotinamida adenina dinucleotídeo reduzido tetrazolium redutase (NADH2-TR); fosfatase ácida (N.AS-BI.P-A a pH 5,0), ácido periódico de Schiff (PAS) com e sem digestão. Foram também realizadas as colorações de hematoxilina e eosina, tricrômico de Gomori modificado, Oil Red e PAS.

\section{RESULTADOS}

Os pacientes foram divididos em três grupos diferentes, de acordo com os resultados encontrados após análise dos fragmentos amplificados por PCR. Grupo 1: alelos normais. Todos aqueles com peso molecular abaixo de $175 \mathrm{pb}$, que corresponde a um alelo de 38 repetições CTG. O alelo mais freqüentemente encontrado neste grupo corresponde a um alelo com 5 repetições CTG $\left(\right.$ alelo $_{5}$ ). Grupo 2: resultados inconclusivos. Foi considerado resultado inconclusivo cada vez que apenas uma banda era visualizada, já que o paciente poderia ser homozigoto para um determinado número de repetições CTG dentro do limite da normalidade ou heterozigoto apresentando um alelo normal e outro expandido acima da capacidade de detecção do protocolo utilizado. Esta banda correspondeu ao alelo $_{5}$ em 8 casos e em 1 caso a um alelo com 12 repetições $\left(\right.$ alelo $\left._{12}\right)$. A amplificação do DNA de um indivíduo afetado, através de PCR, que é portador de uma expansão grande, fornece a visualização de uma única banda dentro dos limites da normalidade e não mostra o alelo maior. Em pessoas aparentemente homozigotas para um alelo pequeno e comum, a presença de um alelo expandido que não foi detectado pode ser excluída através da realização de Southern blot. Grupo 3: alelos expandidos.

Havia 48 pacientes no grupo 1, nove no grupo 2 e três pacientes no grupo 3. Dos 9 pacientes do grupo 2, sete realizaram eletroneuromiografia (ENMG). Este exame foi indicado para os pacientes com resultados inconclusivos na análise molecular utilizada, pois ENMG normal é encontrada em pacientes homozigotos normais para DM, e ENMG com descargas miotônicas é encontrada em pacientes com DM, o que esclareceria o resultado molecular encontrado. Todos estes pacientes apresentaram resultados normais exceto 1 indivíduo que apresentou resultados compatíveis com neuropatia sensitivo-motora, sem descargas miotônicas, o que afastou o possível diagnóstico de DM1 ou DM2. Esta avaliação eletroneuromiográfica excluiu a possibilidade de mutações, maiores do que a capacidade de detecção pela amplificação e análise por PCR, em indivíduos aparentemente assintomáticos, uma vez que a miotonia seria encontrada. Os três pacientes afetados apresentavam DM1 clássica. Seus alelos normais eram: alelo $_{5}$, alelo $_{5}$ e alelo ${ }_{\sim 13}$, respectivamente.

Dos 3 pacientes afetados, 2 foram submetidos à biópsia muscular que mostrou, nos cortes corados pela hematoxilina e eosina, irregularidade no tamanho das fibras, algumas delas atróficas, além da presença de numerosas fibras com núcleos centralizados. Nos cortes corados pelo tricrômico de Gomori, ORO e PAS não foram encontradas alterações. Na reação para fosfatase ácida 
notava-se um leve aumento de atividade em algumas fibras. $\mathrm{Na}$ reação para NADH2-TR notavam-se algumas fibras com aspecto de fibras em roído de traça e algumas fibras em anel. Nas reações para ATPase notava-se evidente atrofia de fibra tipo I, além da presença de algumas fibras tipo II também atróficas. O aspecto morfológico foi compatível com DM.

A partir dos 3 pacientes afetados, 11 indivíduos, parentes próximos, solicitaram investigação através de PCR para DM1, entre os quais foram diagnosticados outros 6 casos.

\section{DISCUSSÃo}

Há muito tempo a catarata é considerada um dos principais indicadores da presença do gene mutado da DM em parentes assintomáticos de pacientes com a doença, e o reconhecimento de que a catarata pode ser a única manifestação clínica serviu como uma das primeiras evidências de que a DM seria uma doença autossômica dominante ${ }^{(10-12,19-20)}$.

Acredita-se que, inicialmente, a catarata da DM consista em opacidades puntiformes, iridescentes, brancas e/ou policromáticas, localizadas principalmente na região da cápsula posterior, preservando a porção central da lente, progredindo para o tipo de catarata em roseta, com espículas radiais, adquirindo, então, aspecto reticular no córtex do cristalino. A catarata madura, no entanto, é indistinguível da catarata nuclear senil $^{(20)}$.

Até o momento, poucos estudos existem na literatura analisando o risco de pacientes com catarata serem portadores de $\mathrm{DM}^{(10,12,19)}$. Em um estudo não encontraram nenhum portador de DM estudando 101 pacientes com catarata ${ }^{(21)}$. Em outro encontraram 6 pacientes com a mutação da DM em 113 pacientes estudados ${ }^{(10)}$. Dois portadores da pré-mutação entre 231 pacientes selecionados foram encontrados em outro estudo $^{(12)}$. Em outro estudo encontraram 10 pacientes, entre 1.400 indivíduos, com a opacificação do cristalino típica da DM mas sem sinais de doença neuromuscular, e em todos eles os dois alelos da DM estavam dentro dos limites da normalidade ${ }^{(19)}$. Os critérios de inclusão de pacientes não foram uniformes, porém, em todos estes estudos o tipo de DM procurado foi o tipo 1 .

Neste trabalho foram encontradas 3 famílias, não aparentadas, entre 60 indivíduos estudados, utilizando os critérios inicialmente propostos ${ }^{(10)} \mathrm{e}$ modificados, já que a informação sobre alterações policromáticas não constava nos prontuários médicos.

De forma global, a proporção de indivíduos afetados com DM nestes estudos é bastante variável e apesar de todos eles basearem a triagem para DM em pacientes com catarata, talvez o principal fator envolvido na disparidade dos resultados encontrados seja a diferença dos critérios utilizados na seleção dos pacientes a serem triados. Uma vez respeitados os critérios propostos ${ }^{(10)}$, este trabalho encontrou resultados semelhantes, ou seja, em cerca de 5\% da população estudada foi encontrado o alelo expandido da DM1.
Oitenta por cento dos pacientes estudados apresentaram resultados normais, com dois alelos de tamanhos diferentes, ambos dentro dos limites da normalidade, sendo o alelo $_{5} \mathrm{o}$ mais freqüentemente encontrado. Para estes pacientes, outra causa que justifique a catarata pré-senil deve ser considerada.

Os resultados encontrados nos pacientes do grupo 2 são, até certo ponto, questionáveis, uma vez que a visualização de apenas uma banda pode significar que ao invés de homozigose, exista um alelo cujo tamanho supere a capacidade de detecção da PCR, e que portanto não esteja sendo detectado. No entanto, numa situação onde um indivíduo com catarata pré-senil, selecionado para triagem de DM, apresente um alelo expandido além da capacidade de detecção deste método, outras manifestações clínicas da DM estariam presentes, como o fenômeno miotônico, detectável através de ENMG, mesmo quando a miotonia não é clinicamente aparente. Por este motivo, estes pacientes foram submetidos a estudo eletroneuromiográfico, na tentativa de encontrar descargas miotônicas, já que os mesmos não apresentavam outros sinais e/ou sintomas de doença neuromuscular, exceto por um único indivíduo. O único paciente que apresentou ENMG alterada, foi o mesmo que tinha sinais e sintomas de doença neuromuscular. A ENMG deste paciente mostrava sinais de polineuropatia, sendo o mesmo encaminhado ao ambulatório de Doenças Neuromusculares do HCFMRP para continuação da investigação diagnóstica. Os pacientes do grupo 2 apresentavam uma banda correspondendo ao alelo ${ }_{5}$, exceto um indivíduo que mostrou uma banda correspondente ao alelo ${ }_{12}$.

$\mathrm{O}$ alelo $_{5}$, o menor e o mais frequiente dos alelos encontrados, apresenta peso molecular menor que $100 \mathrm{pb}$ e maior que $50 \mathrm{pb}$. Utilizando os "primers" descritos ${ }^{(14)} \mathrm{em}$ nosso estudo, um alelo com 5 repetições teria $77 \mathrm{pb}$. Este alelo foi o mais freqüentemente encontrado nos três grupos estudados. Há relato da distribuição dos alelos de DM1 numa população normal, da região de Ribeirão Preto, utilizando as mesmas condições de PCR do presente estudo ${ }^{(22)}$. Eles encontraram 22 alelos de diferentes tamanhos, sendo o alelo de 5 repetições o mais freqüente. Nesta seqüência de alelos, o alelo que corresponde a $98 \mathrm{pb}$, é o alelo que nós chamamos de alelo $_{12}(12$ repetições). Assim sendo, apesar de não ter sido realizado seqüenciamento do fragmento, acreditamos que o alelo $_{5}$ corresponde, de fato, ao alelo com 5 repetições. Estes resultados, assim como o número de repetições CTG presentes, devem ser confirmados através de outras técnicas de investigação molecular, preferencialmente o Southern blot ${ }^{(13-14)}$.

Os resultados da PCR, por si só, não seriam suficientes para conferir o diagnóstico de DM aos pacientes do grupo 3. É importante ressaltar que estes indivíduos haviam sido atendidos e acompanhados no HCFMRP, sendo submetidos a procedimentos cirúrgicos por apresentarem catarata bilateral présenil, sem causa suspeita ou determinada. Quando eles compareceram para participar do estudo de DM1, foi observado que apresentavam sintomas típicos da doença, como fraqueza da musculatura facial e miotonia, portanto os resultados da 
PCR mostrando apenas uma única banda permitiram a confirmação da hipótese diagnóstica, corroborada, em dois pacientes, através de biópsia muscular.

Nenhum destes pacientes tinha conhecimento do diagnóstico, nem de suas implicações, apesar de haver história familiar positiva nos três casos. A investigação de outros membros da família confirmou o diagnóstico de DM em alguns indivíduos e excluiu a possibilidade da doença em outros. O impacto na vida destas pessoas e de seus núcleos familiares foi extremamente importante uma vez que significou uma explicação para as alterações apresentadas por aqueles que tinham alguma manifestação da doença e a tranqüilidade definitiva para aqueles que apresentaram os dois alelos normais.

A importância da detecção do portador de uma pré-mutação ou mutação completa, não pode ser desvinculada da natureza dinâmica destas mutações e que colocam os indivíduos afetados em risco de terem um filho ou neto com a forma clássica e/ou congênita da doença. A detecção do portador de uma pré-mutação ou mutação completa pode auxiliar na prevenção da ocorrência de DM congênita em famílias que desconhecem o diagnóstico de $\mathrm{DM}^{(6)}$. No entanto, o número de pacientes com DM1 obtidos em diferentes triagens relatadas na literatura ${ }^{(12,19-21)}$ é muito baixo para recomendar a triagem molecular da mutação da DM1 em todos os pacientes com catarata.

Este trabalho sugere que a triagem da mutação da DM1 deve ser realizada, mas deve se restringir aos pacientes com menos de 55 anos e com catarata bilateral, sem fator precipitante evidente, exceto por diabete melito tipo 2, como recomendado $^{(10)}$. Por outro lado, sugere-se que os pacientes com catarata policromática bilateral sejam incluídos nesta triagem geral, obedecendo aos mesmos critérios de seleção, e não utilizado como critério à parte, uma vez que esta lesão parece não ser patognomônica da $\mathrm{DM}^{(12,19)}$.

A triagem através de protocolos de PCR padronizados para o gene da DM1 fornece resultados rápidos e confiáveis para a maioria dos indivíduos normais. Os pacientes aparentemente homozigotos para um alelo pequeno e freqüente, precisam continuar a investigação devido à possibilidade da existência de um alelo expandido que não foi amplificado. Neste sentido todos os pacientes com este tipo de resultado devem ser submetidos a exame físico minucioso e o interrogatório de história familiar deve ser dirigida para DM. Se não forem encontradas evidências da doença através do exame físico e/ou da história familiar, é pouco provável que exista um alelo expandido que não foi amplificado e, portanto, é pouco provável que este indivíduo seja portador de uma mutação completa. Por outro lado, se o exame físico e/ou a história familiar forem positivos, o diagnóstico de DM é muito provável e o estudo molecular de outros membros da família pode ajudar na análise dos alelos normais e expandidos que estão sendo segregados na família. De qualquer maneira, os portadores de pré-mutação são detectados através de PCR.
Esta abordagem inicial é sugerida principalmente ao oftalmologista uma vez que o número de pacientes avaliados por catarata, nos Serviços de Oftalmologia, é grande. Àqueles indivíduos detectados como portadores, possíveis ou definitivos, da mutação da DM1, devem ser-lhes oferecido aconselhamento genético e investigação adicional, individual e familiar.

A biópsia de músculo de pacientes com DM não tem nenhuma característica patognomônica da doença, mas apresenta um padrão geral típico cujas características são: aumento no número dos núcleos centrais das fibras musculares, freqüentemente em cadeia; fibras em anel; atrofia de fibras tipo 1; e aumento de fibras nos fusos neuromusculares ${ }^{(23)}$. A biópsia muscular dos pacientes mostrou irregularidade no tamanho das fibras, algumas delas parecendo atróficas, além da presença de numerosas fibras com núcleos centralizados. Notavamse algumas fibras com rarefação da atividade oxidativa, com aspecto de fibra em roído de traça, além de algumas fibras em anel. Nas reações para ATPase parecia haver atrofia importante de fibras tipo 1. Ou seja, o aspecto morfológico foi compatível com DM.

Finalmente, este estudo sugere que a triagem de DM1 em pacientes com menos de 55 anos, com catarata bilateral, sem causa evidente que justifique a lesão, exceto diabete melito tipo 2, deva ser mantida, principalmente considerando que apesar dos pacientes, ocasionalmente, poderem se apresentar com outros sintomas da doença, o diagnóstico pode não ter sido questionado e a causa da catarata continuar indefinida. Esta triagem permite o diagnóstico de pacientes que não se apresentam inicialmente com queixas neurológicas e permite, também, o diagnóstico precoce de pacientes com DM que apresentam apenas catarata.

\section{CONCLUSÕES}

Utilizando o método proposto por Kidd et al, com algumas modificações, este trabalho cumpriu o objetivo de verificar a existência de novas famílias afetadas com DM1.

O diagnóstico de DM1 em 3 indivíduos permitiu que outros 6 indivíduos afetados fossem diagnosticados e 5 indivíduos, em risco de apresentarem a mutação da DM1, fossem evidenciados como sendo normais. Isto permite que através do aconselhamento genético, os mesmos possam fazer seu planejamento familiar conhecendo os riscos de transmitir a doença, inclusive na forma congênita, para sua prole.

$\mathrm{O}$ alelo mais freqüentemente encontrado na população estudada foi o alelo $_{5}$ e que provavelmente corresponde ao alelo com 5 repetições CTG.

Este estudo sugere que deve ser enfatizado aos oftalmologistas, classe médica em geral e profissionais de saúde, que pacientes com catarata bilateral, com até 55 anos de idade, sem causa definida, devem ser encaminhados aos Serviços de Genética Clínica e/ou Neurologia, visando o diagnóstico precoce de pacientes com DM. 


\section{ABSTRACT}

Purpose: To detect MD1 premutation and full mutation carriers among cataract patients and offer familial genetic counseling. Methods: We studied the DNA of 60 selected cataract patients through polymerase chain reaction analysis. This study was performed at the "Hospital das Clínicas da Faculdade de Medicina de Ribeirão Preto" where selected patients had been examined at the Cataract Outpatient Clinic from 01/01/1982 to $30 / 06 / 1995$. Selection criteria were age under 55 with no obvious precipitating factor, except diabetes mellitus type 2 , with or without neuromuscular signs suggestive of myotonic dystrophy. Results: Three patients were found to have a full mutation corresponding to $5 \%$ of the group. Additional affected individuals were found among patients' relatives. No premutation was found. Conclusions: These results emphazise the importance of screening for MD1 gene carriers among cataract patients, and further genetic counselling.

Keywords: Cataract; Diagnosis, differential; Genetic counseling; Myotonic dystrophy

\section{REFERÊNCIAS}

1. Koch HR, Weyner A, Roth E. Anomalies of the lens. In: Emery AEH (ed). Principles and practice of medical genetics. 2nd ed. Edinburgh, New York: Churchill Livingstone; 1991. cap. 46.

2. Buyse ML. Birth defects encyclopedia: the comprehensive, systematic, illustrated reference source for the diagnosis, delineation, etiology, biodynamics, occurrence, prevention, and treatment of human anomalies of clinical relevance. Dover, MA; Cambridge, Mass.: Center for Birth Defects Information Services: Blackwell Scientific; 1990. p.295-6.

3. Ranum LP, Day JW. Dominantly inherited, non-coding microsatellite expansion disorders. Curr Opin Genet Dev. 2002;12(3):266-71. Review.

4. Caskey CT, Pizzuti A, Fu YH, Fenwick RG Jr, Nelson DL. Triplet repeat mutations in human disease. Science. 1992;256(5058):784-9. Review.

5. Wenstrom KD. Fragile $X$ and other trinucleotide repeat diseases. Obstet Gynecol Clin North Am. 2002;29(2):367-88, vii. Review.

6. Harper PS, Harley HG, Reardon W, Shaw DJ. Anticipation in myotonic dystrophy: new light on an old problem. Am J Hum Genet. 1992;51(1):10-6.
7. Passos-Bueno MR, Cerqueira A, Vainzof M, Marie SK, Zatz M. Myotonic dystrophy: genetic, clinical and molecular analysis of patients from 41 Brazilian families. J Med Genet. 1995;32(1):14-8.

8. Harper PS, Rüdel R. Myotonic Dystrophy. In: Engel AG, Franzini-Armstrong C (eds). Myology: basic and clinical. 2nd ed. New York: Mc Graw-Hill; 1994. p.1192-219.

9. Jaspert A, Fahsold R, Grehl H, Claus D. Myotonic dystrophy: correlation of clinical symptoms with the size of the CTG trinucleotide repeat. J Neurol. 1995;242(2):99-104.

10. Kidd A, Turnpenny P, Kelly K, Clark C, Church W, Hutchinson C, et al Ascertainment of myotonic dystrophy through cataract by selective screening. J Med Genet. 1995;32(7):519-23.

11. Brook JD, McCurrach ME, Harley HG, Buckler AJ, Church D, Aburatani H, et al. Molecular basis of myotonic dystrophy: expansion of a trinucleotide (CTG) repeat at the 3 ' end of a transcript encoding a protein kinase family member. Cell. 1992;68(4):799-808.

12. Cobo AM, Poza JJ, Blanco A, Lopez de Munain A, Saénz A, Azpitarte M, et al. Frequency of myotonic dystrophy gene carriers in cataract patients. J Med Genet. 1996;33(3):221-3.

13. McGlennen RC. Dynamic mutations pose unique challenges for the molecular diagnostics laboratory. Clin Chem. 1996;42(10):1582-8. Review.

14. Petronis A, Heng HH, Tatuch Y, Shi XM, Klempan TA, Tsui LC, et al. Direct detection of expanded trinucleotide repeats using PCR and DNA hybridization techniques. Am J Med Genet. 1996;67(1):85-91.

15. Ranum LP, Rasmussen PF, Benzow KA, Koob MD, Day JW. Genetic mapping of a second myotonic dystrophy locus. Nat Genet. 1998;19(2):196-8.

16. OMIM: Online Mendelian Inheritance in Man [homepage on the Internet]. Johns Hopkins University. [cited 2004 Set 13]. Avaliable from: www.ncbi. nlm.nih.gov/entrez/query.fcgi?db=OMIM

17. Wansink DG, van Herpen RE, Coerwinkel-Driessen MM, Groenen PJ, Hemmings BA, Wieringa B. Alternative splicing controls myotonic dystrophy protein kinase structure, enzymatic activity, and subcellular localization. Mol Cell Biol. 2003;23(16):5489-501.

18. Ashizawa T, Dubel JR, Harati Y. Somatic instability of CTG repeat in myotonic dystrophy. Neurology. 1993;43(12):2674-8.

19. Giordano M, Comoli AM, De Angelis MS, Mutani R, Sebastian F, Richiardi PM. Reassessment of the specificity of lens in myotonic dystrophy. Ophthalmic Res. 1996;28(4):224-9.

20. Lane R, Carey N, Orrell R, Moxley RT 3rd. Claude Monet's vision. Lancet. 1997;349(9053):734.

21. Harley HG, Brook JD, Rundle SA, Crow S, Reardon W, Buckler AJ, et al. Expansion of an unstable DNA region and phenotypic variation in myotonic dystrophy. Nature. 1992;355(6360):545-6.

22. Camacho R, Muñoz MVR, Canas MCT, Simões AL. Distribuição de frequiência dos alelos do gene da proteína miotonina-kinase (PMK) em uma população da região de Ribeirão Preto. Br J Genet. 1997;20 Suppl.:F32.

23. Jaspert A, Fahsold R, Grehl H, Claus D. Myotonic dystrophy: correlation of clinical symptoms with the size of the CTG trinucleotide repeat. J Neurol. 1995;242(2):99-104.

\section{ABO ELETRÔNICO}

\section{Acesso: http://www.abonet.com.br}

